\title{
FORMAÇÃO DE JOGADORES DE FUTEBOL: PROCESSO HISTÓRICO E BASES PARA A EVOLUÇÃO NO BRASIL
}

\section{RESUMO}

\author{
${ }^{1}$ Ivan Furegato Moraes \\ ${ }^{2}$ Flávia da Cunha Bastos \\ ${ }^{3}$ Maria José Carvalho
}

O presente artigo objetiva demonstrar como a literatura brasileira descreve a evolução histórica do processo de formação de jogadores de futebol - principalmente com relação aos seus períodos, locais de aprendizagem, agentes educadores e metodologias utilizadas - e apresentar uma síntese histórica de tal processo, suprindo uma lacuna existente nos estudos dessa temática. Para tal foi realizada uma revisão sistemática com base na busca de dissertações, teses e artigos no Portal de Periódicos do Capes. Devido aos poucos estudos localizados foram utilizados trabalhos referenciados nos mesmos e livros sobre o tema. A análise das informações encontradas levou à organização do material em cinco períodos cronológicos que retratam a evolução do processo de formação no Brasil, sendo observado que o mesmo partiu de um modelo elitista - realizado principalmente nos clubes socioesportivos - para um popular - informal e livre, realizado nas ruas e campos de várzea - até se tornar totalmente formalizado - restrito, controlado e baseado em métodos científicos -, sendo realizado nas categorias de base dos clubes tradicionais e dos clubes-empresa com objetivo de formar jogadores para "venda". Esses achados permitiram realizar uma síntese contendo todos os períodos, locais onde a formação ocorre, principais agentes educadores e metodologias de ensino empregadas em cada um deles, a qual pode servir de referencial para futuros estudos e novas pesquisas sobre o tema.

Palavras-chave: futebol; formação de jogadores no Brasil; categorias de base; Certificado de Clube Formador.

\section{SOCCER PLAYERS FORMATION: HISTORICAL AND PROCESS BASES FOR DEVELOPMENT IN BRAZIL}

\begin{abstract}
This article aims to demonstrate how Brazilian literature describes the historical process of soccer player's development - especially regarding periods, learning sites, educational agents and methods. This research also aims to present a brief historical overview on the process, filling a gap on this subject. Thus, we performed a systematic review based on dissertations, thesis, and articles in Capes Periodical Portal. Due to the low number of studies, we used quoted works and books about the subject. The analysis considered the categorization of the material in five chronological periods that depict the evolution of training process in Brazil, which showed that soccer training started with an elitist model - held mainly in social and sports clubs - and evolved to a popular, informal and free practice, held in the streets and informal fields. The sport later became fully formalized - restricted, controlled and based on scientific methods, being held in the development categories of traditional clubs and clubs-company in order to form players "to sell". The findings allow us to achieve a synthesis containing all training periods, leading educational agents and teaching methodologies employed in each of them, which may serve as reference for future studies and new researches.
\end{abstract}

Keywords: Soccer, player's development in Brazil, Development of categories, Certificado de Clube Formador (Trainer Club Certificate).

\footnotetext{
${ }^{1}$ Doutorando em Educação Física e Esporte pela Universidade de São Paulo - USP, São Paulo, (Brasil). Experiência na Área de Comunicação, com Ênfase em Marketing, e em Gestão e Eventos Esportivos.

E-mail: ifuregato@gmail.com

${ }^{2}$ Doutora em Educação pela Universidade de São Paulo - USP, São Paulo, (Brasil). Professora Assistente do Departa mento de Esporte da Escola de Educação Física da Universidade de São Paulo - USP.E-mail: flaviacb@usp.br ${ }^{3}$ Doutora em Ciências do Desporto pela Faculdade de Desporto da Universidade do Porto - U. PORTO, (Portugal).

Professora da Universidade do Porto - U. PORTO. E-mail: mjc@fade.up.pt
} 


\section{INTRODUÇÃO}

O futebol no Brasil, desde a sua introdução no final do século XIX, encontrou terreno fértil para prosperar, tornando-se ao longo do século XX - e até os dias atuais - a principal modalidade esportiva brasileira, bem como um símbolo do país e um traço da identidade nacional (Mascarenhas, 2014).

Inicialmente a modalidade era praticada apenas pela elite, principalmente a paulistana e carioca (Santos Neto, 2002). Contudo, durante as primeiras décadas do século XX o futebol populariza-se e as camadas sociais inferiores o adotam como forma de lazer, tanto praticando como assistindo aos jogos (Franzini, 2003).

Com o reconhecimento legal da profissão de jogador de futebol na década de 1930, a modalidade passou a ser vista como uma opção de trabalho que poderia proporcionar ascensão social e financeira a uma camada da população que, sem estudo, possuía poucas possibilidades de emprego e renda (Damo, 2007; Mascarenhas, 2014; Rocha et al., 2011).

$\mathrm{O}$ aumento do interesse da população pelo futebol, a criação de novas equipes e o acirramento da rivalidade entre elas e a profissionalização - e seus benefícios - aumentaram a demanda por jogadores e o interesse de parte da população masculina infantil e jovem, principalmente das grandes cidades, em tornar-se jogadores profissionais, fato potencializado pelos talentosos jogadores que inspiravam os mais jovens e pelas conquistas da seleção brasileira (Damo, 2007; Mascarenhas, 2014; Rodrigues, 2003).

O crescimento do futebol e da demanda por atletas profissionais fez com que a formação de jogadores ganhasse importância no Brasil, principalmente a partir da década de 1970, quando a mesma passou a ser tratada como fundamental para garantir o surgimento de atletas talentosos e em quantidade suficiente para suprir o mercado e possibilitar a continuidade e expansão do futebol brasileiro (Mascarenhas, 2014; Rodrigues, 2003).

A formação esportiva é o processo em que ocorre a especialização do jovem em uma determinada modalidade, sendo realizado de forma longa, minuciosamente planejada e equiparada a um curso superior, visando converter jovens talentos em profissionais capazes de exibir suas performances publicamente (Carraveta, 2012; Damo, 2007; Thiengo, 2011). Rodrigues (2003, p. 17) complementa, afirmando que a formação esportiva é "resultado de um processo pedagógico e civilizatório caracterizado pela regulamentação, controle, institucionalização e racionalização desta profissão".

Sobre a formação do jogador de futebol no Brasil, a mesma possui caráter profissional e multidisciplinar (Carraveta, 2006) e, apesar de ainda existir a crença de que o talento nato é imprescindível (Cavichiolli et al., 2011; Gaspar, 2011; Rodrigues, 2003), o processo de formação é uma tecnologia altamente desenvolvida, construído em meio à espetacularização do futebol (Damo, 2007) e baseado em princípios coerentes e progressivos com estabelecimento de uma forma padrão de jogo (Casarin \& Streit, 2011).

A especialização no futebol objetiva o aperfeiçoamento das habilidades técnicas e motoras, a correção de problemas e vícios oriundos da pré-formação, o ensino das táticas do jogo para a criação de uma cultura tática e a priorização do jogo coletivo (Carraveta, 2012; Paoli, 2007; Rodrigues, 2003; Scaglia, 1996).

Casarin and Streit (2011) completam, afirmando que a formação é um fenômeno complexo, composto por diversas dimensões que interagem entre si constantemente, objetivando o desenvolvimento das dimensões tática, técnica, física, psicológica, educacional e social por meio da interação entre o jovem atleta e diversos agentes como a sociedade, a cultura, a equipe, os demais jogadores, treinadores, dirigentes, funcionários dos clubes, pais e torcedores.

A importância da formação de futebolistas no Brasil não ocorre apenas na vertente esportiva, mas também na social, com a mesma atuando como agente educador dos jovens, que a frequentam durante a infância e adolescência, período fundamental no processo educacional, de formação do caráter e preparação para a vida adulta (Damo, 2007; Melo, 2008; Rodrigues, 2003). A formação também contribui para afastar os jovens de problemas crescentes da sociedade, como a violência e as drogas (Melo, 2008; Santos et al., 2011), sendo que de certa forma assume parte do papel das famílias e da escola no processo de formação dos jovens brasileiros (Campestrini, 2009; Rodrigues, 2003; Scaglia, 1996).

Além da importância esportiva e social, a formação de futebolistas possui relevância financeira, não só para os jogadores que adquirem uma profissão capaz de lhes garantir uma fonte de renda (Damo, 2007), mas para toda a economia brasileira. Dados da Confederação Brasileira de Futebol (CBF) apontam que, entre 2011 e julho de 2015, 1.728 jogadores foram negociados para o exterior, gerando receitas de $\mathrm{R} \$ 1,405$ bilhões (Assessoria CBF, 2015a).

Apesar de toda a relevância citada, foi constatado um limitado número de estudos acadêmicos sobre a evolução histórica do processo de formação no Brasil, os locais de aprendizagem, os agentes de formação e as metodologias utilizadas, temas que por muitos anos foram relegados a um segundo plano nos meios acadêmicos, apesar da existência de trabalhos como o de Damo (2007) e o de Rodrigues (2003).

De se ressaltar ainda que os poucos estudos localizados não foram produzidos por pesquisadores ligados à gestão do esporte, mas sim a diversas áreas acadêmicas, o que talvez justifique por que a temática apresentada não é tratada de forma central, sistematizada e 
direta. Tal situação dificulta uma visão ampla e o pleno entendimento de todo o processo histórico de formação de futebolistas no Brasil, diferentemente de outros pontos do futebol brasileiro amplamente estudados, como a evolução histórica das leis esportivas (Silva, 2008) e dos campeonatos (Santiago Júnior, 2006).

Em paralelo, os atuais problemas técnicos e financeiros do futebol brasileiro, principalmente os fracos resultados da seleção, que ocasionaram uma drástica queda no Ranking de Seleções da Fifa (Lance! Contéudos, 2016), fizeram com que o processo de formação fosse evidenciado e analisado mais profundamente pela mídia, governo e sociedade, sendo alvo de questionamentos e críticas (Amora, 2013; Campestrini, 2009; Coelho, 2014a, 2014b; Sapienza, 2011), além de alterações legais (Brasil, 2011; Melo Filho, 2011).

A partir de tal cenário e da citada ausência de trabalhos acadêmicos que abordem de forma ampla e direta a evolução histórica do processo de formação de jogadores de futebol no Brasil, emergiram duas questões que motivaram a realização do presente estudo: (i) como a literatura brasileira descreve a evolução histórica do processo de formação de jogadores de futebol, em especial sobre as etapas, os locais de aprendizagem, os agentes educadores e as metodologias empregadas?; e (ii) a partir de tal descrição é possível elaborar uma síntese do processo histórico de formação de futebolistas no Brasil?

Com base em tais indagações, foi definido o objetivo central, que foi levantar e identificar a literatura brasileira produzida sobre o processo de formação de futebolistas no Brasil e descrever de forma ampla, direta e concisa como a mesma ocorreu, com ênfase nos locais, agentes educadores e nas metodologias utilizadas. A partir da análise do material obtido, foi elaborada uma síntese, contribuindo para a compreensão do atual momento da formação no país.

\section{METODOLOGIA}

Para responder às questões e cumprir os objetivos foi realizada uma revisão sistemática qualitativa (Gomes \& Caminha, 2014) da literatura acadêmica brasileira desde a introdução da modalidade no país até os dias atuais, com ênfase nos principais locais de ensino, agentes educadores e nas metodologias utilizadas.

Foi concretizada uma busca nas bases de dados indexadas no Portal de Periódicos da Coordenação de Aperfeiçoamento de Pessoal de Nível Superior (CAPES) com os seguintes descritores: "formação futebol"; "histórica formação futebol"; "formação jogador futebol"; "processo formação jogador futebol”; "histórico processo formação jogador futebol"; "evolução histórica formação jogador futebol"; e "etapas formação jogador futebol", sendo os mesmos aplicados aos campos título e assunto, não havendo restrições quanto à data de publicação.

Das buscas foram excluídos artigos de revistas comercias e de opinião e selecionados artigos, revisados por pares ou não, dissertações e teses, que totalizaram 226 trabalhos. A partir da leitura do conteúdo dos resumos, foram selecionados 50 artigos/dissertações/teses diretamente relacionados ao tema da pesquisa. Uma nova seleção foi realizada, com a retirada dos registros duplicados e nova verificação da relação com a temática por meio da leitura completa dos trabalhos restantes. Nessa etapa, foram selecionados 12 artigos (Casarin \& Streit, 2011; Cavichiolli et al., 2011; R. M. Cruz, 2012; R. T. Cruz, 2011; Gaspar, 2011; Pedroza Junior, 2013; Pazzin, 2014; Pimenta, 2000; Rocha et al., 2011; Santos et al., 2011; Soares et al., 2011; Solder et al., 2010), cinco dissertações (Ferreira, 2010; Rodrigues, 2003; Spaggiari, 2009; Stédile, 2011; Thiengo, 2011) e duas teses (Damo, 2007; Rodrigues, 2007), todos analisados integralmente.

Também foi realizada consulta às referências dos trabalhos selecionados para identificar outras fontes de informações, ampliando e complementando a pesquisa. Foram localizados, analisados e inclusos nessa etapa um trabalho de conclusão de curso (Casarin \& Cella, 2008), cinco dissertações (Campestrini, 2009; Melo, 2008; Moraes, 2015; Souza, 2008; Wilpert, 2005), duas teses (Paoli, 2007; Toledo, 2000) e quatro artigos (Ferreira \& Paim, 2011; Montagner \& Oliveira Silva, 2003; Scaglia, 1996; Valentin \& Coelho, 2005).

Ainda de forma a expandir as fontes de pesquisa, foram utilizados livros sobre a formação de futebolistas no Brasil, sendo localizadas e analisadas nove obras (Aidar \& Leoncini, 2002; Brunoro \& Afif, 1997; Carraveta, 2006, 2012; Franzini, 2003; Mascarenhas, 2014; Melo Filho, 2011; Santos Neto, 2002; Sarmento, 2006).

\section{RESULTADOS}

A apresentação das informações obtidas se dá a partir da sua compilação por períodos cronológicos, visando demostrar a evolução histórica do processo de formação no Brasil. Tal divisão foi escolhida por permitir uma melhor apresentação dos fatos e desde já admitimos que, por se tratar de uma visão evolutiva, alguns fatos e processos ocorrem simultaneamente e/ou ao longo de vários anos.

A determinação dos períodos foi realizada com base em marcos históricos identificados nas informações coletadas, sendo os mesmos escolhidos por serem relacionados a fatos que ocasionaram e/ou provocaram mudanças no futebol mundial e/ou brasileiro, afetando diretamente o processo de formação no Brasil. 
$1880-1930$

A formação de jogadores no Brasil iniciou-se com a introdução do futebol nas duas últimas décadas do século XIX (Santos Neto, 2002). Diferentemente de outros países, especialmente os sul-americanos, a implementação e o ensino da modalidade ocorreu de forma dispersa e sem conexão entre os diversos pontos do território (Mascarenhas, 2014).

Assim, ambos os processos foram realizados por uma variedade de agentes propagadores e lecionadores, sendo possível apontar cinco principais: marinheiros ingleses; escolas; imigrantes europeus; jovens estudantes brasileiros; e os próprios praticantes (Franzini, 2003; Mascarenhas, 2014; Santos Neto, 2002; Souza, 2008).

Os marinheiros ingleses foram os primeiros a praticar e ensinar, informalmente, o futebol no Brasil, pois ao atracarem nos portos jogavam, apresentando a modalidade à população, que aprendia por observação (Mascarenhas, 2014).

Outro agente propagador foram as escolas, principalmente as ligadas à Igreja Católica, que, visando aperfeiçoar o ensino, adotaram novas técnicas de educação importadas da Europa. Entre elas estava a adoção das aulas de Educação Física, com o futebol sendo uma das principais modalidades lecionadas pelos padres e professores. Contudo, cabe a ressalva de que era incentivada a prática educacional e recreativa, sem promover a criação de equipes e a competição (Santos Neto, 2002; Souza, 2008).

Merece destaque o Colégio São Luiz, então localizado em Itu, no interior de São Paulo, pois o mesmo era frequentado por membros da elite de todo o país, que se tornaram professores e disseminadores do futebol ao introduzi-lo nas localidades de origem (Santos Neto, 2002).

A prática do futebol passou a integrar o sistema educacional e diversas escolas incentivaram a prática quase que obrigatoriamente. Rosenfeld (1993, cit. por Rodrigues, 2003, p. 22) e Mário Filho (2003, cit. por Souza, 2008, p. 42) citam que a modalidade obteve muitos adeptos no Colégio Vicente de Paula, de Petrópolis, e no Colégio Militar, no Ginásio Nacional, no Colégio Abílio, no Alfredo Gomes e no Anglo-Brasileiro, todos localizados no Rio de Janeiro.

Todavia, a prática realizada nos colégios não teve grande continuidade fora dos muros escolares, pois, como citado, ela não era voltada à competição e os exalunos frequentemente a abandonavam devido às obrigações da vida adulta e profissional (Souza, 2008).

O desenvolvimento do futebol competitivo começou com os imigrantes europeus, principalmente ingleses, que propagavam e ensinavam a modalidade entre os demais imigrantes e alguns brasileiros, principal- mente nos clubes e fábricas (Stédile, 2011), onde os empresários incentivavam a formação de equipes e competições entre fábricas (Mascarenhas, 2014).

Os principais responsáveis pelo desenvolvimento da vertente competitiva foram os jovens da elite brasileira, que, ao voltarem dos estudos na Europa, introduziam e ensinavam o futebol nas suas cidades de origem (Franzini, 2003; Mascarenhas, 2014).

Esses jovens criaram equipes e competições, além de ensinarem a novos praticantes no âmbito dos clubes socioesportivos. Destaque para Charles Miller, considerado popularmente como o introdutor oficial do futebol no Brasil ao desenvolver a modalidade nos clubes da elite paulistana (Franzini, 2003).

Depois de aprender, o próprio praticante se tornava um propagador e professor de futebol, permitindo o rápido crescimento da modalidade inclusive nas classes populares, que também aprendiam observando as partidas e jogando de maneira improvisada (Mascarenhas, 2014).

Por fim, merece destaque que durante esse período o processo de aprendizagem era realizado de forma natural, sem uma didática específica, com pouca supervisão e com o foco no ensino dos fundamentos e das regras visando aumentar o número de praticantes e permitir a continuidade da modalidade.

\section{$1930-1966$}

A partir da década de 1930 o futebol populariza-se devido ao surgimento de novas equipes - muitas populares -; ao aumento da quantidade de jogos; à criação de campeonatos; e ao consequente aumento de praticantes, principalmente entre as classes populares, ocasionado a perda do caráter elitista inicial (Mascarenhas, 2014).

A popularização e a criação da rivalidade entre equipes da mesma cidade aumentaram a competitividade e a demanda por atletas - independentemente da classe social e raça. Para atrair os melhores, eram efetuados pagamentos de prêmios e salários, originando o irreversível processo de profissionalização do futebol, que ao seu fim criou uma nova possiblidade de trabalho e ascensão social para os jovens de origem popular (Damo, 2007; Franzini, 2003; Wilpert, 2005).

A possibilidade de o futebol ser uma profissão rentável, aliada a poucas opções de lazer e até ao limitado acesso às escolas, ocasionou um aumento do número de praticantes, principalmente entre os jovens das classes populares, que praticavam sem a mesma organização e estrutura dos clubes socioesportivos da elite através de formas simples de jogo (Damo, 2007; Mascarenhas, 2014). 
Dentre as diversas maneiras simplórias de prática, surge a "pelada", forma de jogo popular realizada em locais improvisados como quintais, praias, praças, terrenos baldios, ruas e várzeas de rios, com utilização de bolas de diferentes materiais e tamanhos e com equipes que possuíam um número variado de jogadores conforme a disponibilidade do momento, com muitos jogando sem camisa, originando, assim, a expressão "pelada" (Damo, 2007; Mascarenhas, 2014; Montagner \& Oliveira Silva, 2003; Wilpert, 2005).

As "peladas" possibilitaram que os jovens, principalmente das classes populares, aprendessem e praticassem sem a necessidade de uma estrutura completa, algo difícil e caro à época (Damo, 2007). Nesses jogos improvisados os jovens aprendiam praticando, sem a presença de professores e metodologia e com extrema criatividade, liberdade e improviso, características que serviram de base para o surgimento do estilo de jogo brasileiro conhecido como "futebol arte" (Montagner \& Oliveira Silva, 2003; Paoli, 2007; Rodrigues, 2003).

Assim, as "peladas" e as demais formas simplórias de prática do futebol, realizadas principalmente nas ruas e nos campos de várzea, tornaram-se os principais locais de formação de futebolistas (Casarin \& Streit, 2011; Pimenta, 2000).

Tal alteração foi potencializada pelo fato de que a prática do futebol nos clubes socioesportivos da elite, até então principais locais de formação, foi perdendo espaço para outros esportes considerados ainda como nobres, visto que a popularização da modalidade expôs o preconceito e levou parte dos jovens da elite a desejar manter distanciamento do restante da população e, assim, afastando-se da prática futebolística (Damo, 2007).

Durante esse período, as equipes concediam pouca importância à formação, aos treinamentos e à preparação física, que não eram baseados em métodos científicos e nem planejados com exatidão, com a prática da modalidade ocorrendo apenas duas ou três vezes por semana, no final da tarde (Brunoro \& Afif, 1997; Rodrigues, 2003).

Tal postura era justificada pelo pensamento de que o sucesso era fruto apenas do talento individual (Rodrigues, 2003), sendo que "jogadores 'nasceram feitos' e não precisariam passar pelos constrangimentos impostos pelos exercícios coordenados" (Toledo, 2000, p. 136).

Para captar novos atletas, as equipes, cientes de que os jogadores talentosos provinham das "peladas" das várzeas e das ruas, passaram a observar esses jogos

\footnotetext{
4 “Olheiro", ou observador técnico, é o profissional que acompanha os campeonatos amadores, de formação e as "peneiras" buscando jovens talentosos que possam ser encaminhados para os clubes. Tal profissão é realizada na maioria das vezes por ex-atletas, sendo essa uma forma de trabalho para os mesmos após o término da
}

e realizar processos seletivos (Paoli, 2007; Pimenta, 2000; Wilpert, 2005).

Tais processos, criados principalmente devido à grande demanda de solicitações de avaliações (Paoli, 2007), são popularmente conhecidos como "peneiras" e definidos por Montagner \& Oliveira Silva (2003) como:

um processo de seleção empírico, no qual um grande número de crianças e adolescentes são avaliados por clubes, sendo a forma mais tradicional de captação de atletas para o futebol brasileiro. Basicamente, consiste na divisão dos garotos que procuram os processos de seleção em "times", e, sob a supervisão de um "olheiro"4, "boleiro"5 ou ex-jogador, os garotos jogam por um tempo determinado nas posições táticas e são analisados pelos observadores em suas qualidades técnicas e físicas para compor as equipes de base dos clubes. (Montagner \& Oliveira Silva, 2003, p. 195)

O início da consolidação do modelo de formação livre, informal e popular realizado na rua e na várzea ocorreu por meio da campanha da seleção brasileira na Copa do Mundo de 1938, sendo composta por diversos jogadores dotados de uma técnica individual apurada, como Leônidas da Silva (Paoli, 2007).

A visão de que o talento era nato e que os jogadores eram artistas com um dom, não sendo necessária uma metodologia de ensino e treinamento, foi maximizada com a conquista da Copa do Mundo de 1958, que possibilitou o reconhecimento mundial dessa filosofia de formação, ratificada pela conquista do bicampeonato mundial, em 1962 (Damo, 2007; Rodrigues, 2003).

\section{$1966-1990$}

O fraco desempenho brasileiro na Copa do Mundo de 1966, na qual a seleção foi surpreendida por um estilo de jogo conhecido como "futebol força" - baseado no coletivo, na preparação física, na forte marcação e em esquemas táticos -, aliado à deficiente preparação física e a diversos maus hábitos e comportamentos dos jogadores brasileiros, iniciou discussões sobre a necessidade de modernização do futebol no Brasil (Paoli, 2007; Rodrigues, 2003; Valentin \& Coelho, 2005).

A corrente modernizadora era favorável à adoção do modelo de jogo europeu e de teorias científicas, sendo comandada por Cláudio Coutinho e Carlos Alberto Parreira, preparadores físicos da seleção vitoriosa

carreira futebolística (Montagner \& Oliveira Silva, 2003).

5 "Boleiro", na linguagem futebolística brasileira, diz respeito ao jogador de futebol possuindo normalmente uma conotação pejorativa e não profissional. 
na Copa de 1970. Esses profissionais pregavam que o corpo humano era comparável a uma máquina, que deveria ser cuidada e controlada para evitar excessos, além da adoção de rígidos esquemas táticos que exigiam maior comprometimento dos atletas visando o resultado final, que passava a ser mais importante do que o jogo em si. Defendiam a posição de que a implementação de tais mudanças deveria começar pelo processo de formação dos jogadores (Rodrigues, 2003).

Em paralelo, ocorriam grandes alterações na sociedade brasileira ao longo da década de 1970 e 1980 , como o aumento do tempo dedicado ao trabalho; crescimento do número de escolas e maior acesso a elas; expansão urbana e imobiliária; aumento gradual e contínuo da violência; e advento de novos recursos tecnológicos que possibilitaram a ampliação e consolidação da televisão como forma de lazer de grande parte da população urbana. Essas mudanças contribuíram para uma diminuição do tempo livre da população e, consequentemente, da prática do futebol. Outro fator contribuinte para a redução da prática popular foi o crescente desaparecimento dos campos de várzea, que, aos poucos, foram destruídos devido à expansão imobiliária, contribuindo, assim, para uma gradativa redução da importância da rua e da várzea no processo de formação dos jogadores (Aidar \& Leoncini, 2002; Casarin \& Streit, 2011; Gaspar, 2011; Paoli, 2007; Pimenta, 2000; Rodrigues, 2003; Wilpert, 2005).

As mudanças na sociedade, o enfraquecimento da rua e da várzea como locais de formação e o crescimento do "futebol força" - que exigia uma formação e preparação dos atletas controlada e baseada em métodos científicos - levaram os clubes, no início da década 1970, a assumirem o papel de responsáveis pela formação dos jogadores (Aidar \& Leoncini, 2002; Casarin \& Streit, 2011; Damo, 2007; Ferreira, 2010). Assim, segundo Florenzano (1998, cit. por Paoli, 2007, p. 66), o processo de formação passou a ser realizado dentro dos clubes, com a supervisão dos recém-criados Departamentos de Formação/Base.

Para lidar com a nova responsabilidade, os clubes criaram as escolinhas de futebol, espaços nos quais crianças e adolescentes aprendiam da maneira considerada correta, objetivando a formação de jogadores profissionais (Casarin \& Cella, 2008; Ferreira \& Paim, 2011; Melo, 2008). Dessa forma, é possível observar uma significativa mudança no processo de formação, "de um modelo mais liberto, lúdico e artístico para um modelo mais rígido e cerrado" (Casarin \& Streit, 2011, p. 46), realizado de forma prolongada durante o final da infância e a adolescência com base metodológica e científica (Carraveta, 2006).

\footnotetext{
${ }^{6}$ Destaque para a Lei $n^{\circ} 6.354 / 1976$ que, no Artigo 27, garantiu aos ex-atletas que tenham atuado profissionalmente por três anos consecutivos ou por cinco anos al-
}

As escolinhas tornaram-se espaços especializados para a formação de jogadores, "locais onde se ensina a jogar futebol, de preparação e seleção de talento para o futebol profissional, de produção social do corpo dos atletas, mediante um conjunto de treinamentos" (Rodrigues, 2007, p. 107) que visam a educação técnica, física e tática, bem como a aprendizagem dos esquemas táticos e das formas de jogo.

As escolinhas obtiveram uma rápida aceitação e expansão na década de 1970, sendo valorizadas não só pelos clubes, mas também pela imprensa, como exposto no seguinte trecho de matéria publicada em 1972 pela Revista Placar (1972, cit por. Rodrigues, 2007, p. 103):

Como todo profissional, o jogador de futebol deve ter uma educação especializada [...] e hoje o "craque feito em casa" já é tão ou mais comum que o "craque descoberto" na várzea ou no interior.

Com a consolidação das escolinhas durante a década de 1970, o jogador formado na rua e na várzea foi desvalorizado e considerado "um analfabeto no futebol, estranho, sem cultura tática nem conhecimentos de fundamentos futebolísticos" (Rodrigues, 2003, p. 103). Tal visão é corroborada por Valentin \& Coelho (2005), que apontam que:

\begin{abstract}
o jogador que se apresentasse a uma equipe federada deveria ter cumprido toda a seriação das escolinhas de futebol, de preferência as que fossem reconhecidas pelos treinadores por sua competência no ato de disciplinar e domesticar os jogadores através de uma intervenção pontual e detalhista. (Valentin \& Coelho, 2005, p. 187).
\end{abstract}

A criação e expansão das escolinhas abriu um novo campo de trabalho para os ex-jogadores, que, na maioria, não possuíam uma formação educacional completa devido às exigências da carreira de atleta de futebol. Assim, o ensino do futebol ${ }^{6}$ torna-se uma forma de garantir a sobrevivência, tanto trabalhando para os clubes como abrindo suas próprias escolinhas - visto que as escolinhas "oficiais" não conseguiam atender à crescente demanda - e obtendo receitas por meio da cobrança de mensalidades e pela indicação de atletas aos clubes (Melo, 2008; Thiengo, 2011).

Paralelamente, com o advento do "futebol força", houve uma valorização dos preparadores físi$\cos ^{7}$, que, juntamente com a ampliação e desenvolvi-

ternados a função de Monitor de Futebol, que se aproximava da função de treinador, legitimando a atuação dos mesmos na formação de atletas.

${ }^{7}$ Em que pese a importância da profissão de preparador físico, a mesma só foi regulamentada em 1998 por 
mento dos cursos de graduação em Educação Física, levou tais profissionais a buscarem oportunidades nas escolinhas, locais onde era possível a aplicação prática das pesquisas acadêmicas, acelerando a adoção de metodologias científicas no ensino do futebol (Damo, 2007; Pimenta, 2000; Scaglia, 1996).

Nesse cenário surge o embate, até hoje existente, entre ex-jogadores, que acreditam que o conhecimento prático sobressai à teoria científica, e profissionais de Educação Física, que defendem o uso de teorias e metodologias ao invés do empirismo dos ex-atletas (Damo, 2007; Pimenta, 2000; Scaglia, 1996; Solder et al., 2010; Toledo, 2000).

Ao longo da década de 1980 os clubes brasileiros iniciaram um processo de modernização para aperfeiçoar a formação e o treinamento dos atletas profissionais. Nesse período foram criados os Centros de Treinamento $(\mathrm{CTs})^{8}$, considerados por Rodrigues (2003) laboratórios para a formação e preparação dos atletas para um futebol cada vez mais competitivo.

Com o advento dos CTs, os clubes passaram a contar com uma estrutura para a formação de atletas, possibilitando o desenvolvimento integrado de fatores físicos, psicológicos, técnicos e táticos. Nesses centros foram construídos alojamentos para os atletas, principalmente em formação - com idades a partir dos 12 anos , oriundos de outras cidades. Tais jovens passaram a residir nas instalações dos clubes com o objetivo de se tornarem jogadores profissionais (Paoli, 2007), pavimentando o caminho para a transformação do processo de formação e a comercialização de atletas, principalmente para o exterior, em um rentável negócio.

\section{$1990-1998$}

A partir do início da década de 1990, a expansão do futebol pelo mundo ganha força novamente e a modalidade se desenvolve através de diferentes atividades associadas à indústria do entretenimento, gerando grande movimentação econômica. A globalização da economia mundial se reflete nessa indústria e nos segmentos que a compõem, dentre eles o esporte e o futebol, como espetáculo, com a transformação das partidas e dos campeonatos em grandes eventos transmitidos e

meio da Lei ${ }^{\circ}$ 9.696, que também criou o Conselho Federal de Educação Física (CONFEF), responsável pelo controle da profissão.

${ }^{8}$ Merece destaque o São Paulo Futebol Clube, apontado por Toledo (2000) como o primeiro clube do Brasil a possuir um completo CT, inaugurado no final da década de 1980. Fruto da reestruturação e modernização do departamento de futebol do clube, o CT da Barra Funda possibilitou a aplicação de novas técnicas de medicina assistidos mundialmente, aumentando a competitividade e as receitas dos clubes. Nessa nova realidade, a demanda por jogadores aumenta e os mesmos passam a ser tratados como commodities, altamente valorizadas no crescente mercado futebolístico internacional, ocasionando um aumento da procura e contratação dos brasileiros - considerados a época os melhores jogadores do mundo - por equipes do exterior, principalmente europeias (Campestrini, 2009).

Assim, a formação de jogadores transforma-se em um rentável negócio para os praticamente falidos clubes brasileiros, pois, além de abastecer a equipe principal, gerava recursos fundamentais para a sobrevivência dos mesmos (Campestrini, 2009; Mascarenhas, 2014).

Para aprimorar o processo de formação de jogadores e cumprir objetivos sociais, as escolinhas foram naturalmente se caracterizando em três tipos: escolinhas seletivas clubísticas ou categorias de base; escolinhas seletivas privadas; e escolinhas não seletivas (Casarin \& Cella, 2008; Damo, 2007; Melo, 2008; Valentin \& Coelho, 2005), que serão detalhadas a seguir.

\section{Escolinhas Seletivas Clubísticas (categorias de base)}

Derivadas diretamente das escolinhas iniciais, as categorias de base são de propriedade dos clubes e voltadas para a fase final da formação, entre os 14 e 20 anos. Com o advento dos CTs, elas se tornaram mais especializadas e fechadas, direcionadas apenas para os jovens com talento e capacidade para serem profissionais (Damo, 2007).

As categorias de base visam a correção de vícios futebolísticos dos jovens ${ }^{9}$, além de prepará-los para o trabalho físico, ensiná-los como jogar e a respeitar os esquemas táticos, além de adequá-los às normas do clube e do mercado de trabalho (Casarin \& Cella, 2008; Ferreira \& Paim, 2011), em um processo com elevada cobrança por desempenho e vitórias.

Grande parte dos clubes possui categorias de base, que se tornam o principal local de formação de jogadores profissionais, não sendo encontrados mais jogadores formados apenas nas "peladas" de rua e/ou várzea (Rodrigues, 2003). No Quadro 1 apresentamos as principais características das escolinhas seletivas clubísticas dos principais clubes brasileiros.

esportiva e fisiologia à formação e aos treinamentos, garantindo ao São Paulo a hegemonia do futebol brasileiro no início da década de 1990, com seu CT considerado até hoje um exemplo para as demais equipes brasileiras. ${ }^{9}$ Cabe ressaltar que os jovens jogadores chegam normalmente às categorias de base aos 14 anos, com uma formação prévia que muitas vezes é composta por diversos erros e vícios que impossibilitam o seu completo desenvolvimento. 
Quadro 1 - Características das categorias de base dos clubes

Campos de treinamento bem cuidados e em número suficiente;

Materiais esportivos adequados fornecidos pelo clube;

Vestiários equipados utilizados antes e depois da prática esportiva;

Sala de musculação, reunião e para comissão técnica;

Busca do retorno financeiro, porém sem custos aos atletas;

Competições durante toda a temporada;

Comissão técnica completa e adequada à cada categoria;

Metodologia de ensino/treinamento que visa a aquisição dos aspectos físico, técnicos e táticos para a formação de um jogador completo.

Fonte: adaptado de Casarin and Cella (2008) e Moraes (2015).

\section{Escolinhas Seletivas Privadas}

As escolinhas seletivas privadas derivam das escolinhas criadas, fora dos clubes, predominantemente pelos ex-atletas, sendo direcionadas para crianças e adolescentes no período da pré-formação, entre os seis e 14 anos (Casarin \& Cella, 2008).

Os ex-atletas, beneficiando-se da fama enquanto jogadores, abrem tais escolinhas com o objetivo de terem uma ocupação e renda, atraindo jovens que acreditam que o prestígio e a proteção dos donos de tais estabelecimentos irão garantir-lhes um acesso às categorias de base e uma futura profissionalização (Ferreira, 2010; Scaglia, 1996). Melo (2008) aponta que tais escolinhas, apesar do caráter essencialmente comercial, contribuem para a formação educacional e social dos jovens.

Tal formato também foi adotado pelos clubes, com a criação de escolinhas voltadas para a pré-formação, objetivando atender a grande demanda de pedidos, inclusive políticos, de inclusão de jovens nas categorias de base (Damo, 2007; Rodrigues, 2003).

Alguns clubes desenvolveram o formato de franchising para as escolinhas que visa a geração de receitas; divulgação da marca; aumento do número de torcedores e aproximação dos mesmos; e, talvez, a detec- ção de algum talento que possa ser aproveitado nas categorias de base, gerando lucros também para o dono de cada unidade. $\mathrm{O}$ modelo de franquias obteve grande aceitação pelo mercado e pela população e foi implementado não só nas cidades de origem dos clubes, mas por todo o país, e até mesmo no exterior, como no caso das escolinhas das principais equipes brasileiras (Damo, 2007; Rodrigues, 2003).

Com a valorização e glamourização da profissão de jogador de futebol, as escolinhas seletivas privadas conquistaram espaço não só entre as camadas populares - nas quais os pais empenham um grande esforço para manter os filhos em tais estabelecimentos, com a esperança de que a carreira deles os sustentem no futuro -, mas também na classe média, que, além de vislumbrar os altos salários que o talento dos filhos pode gerar, passou a ver nessas escolinhas uma forma de atividade física e social saudável, visto a impossibilidade da prática esportiva nos antigos espaços utilizados pelas crianças, como as ruas (Carraveta, 2006; Damo, 2007; Mascarenhas, 2014; Pazzin, 2014; Rodrigues, 2003; Spaggiari, 2009).

No Quadro 2 apresentamos as principais características das escolinhas seletivas privadas.

\section{Quadro 2 - Características das escolinhas seletivas privadas}

Normalmente possuem apenas um campo de treinamento em condições razoáveis, utilizado por diversas categorias com possibilidade de ser de grama sintética;

Materiais esportivos adequados comprados pelos pais;

Vestiários simples utilizados normalmente apenas antes da prática esportiva;

Busca do retorno financeiro com cobrança de mensalidades e outras taxas; Competições esporádicas;

Comissão técnica formada pelo técnico/professor com a possibilidade de um assistente;

Metodologia de ensino/treinamento confusa, indo desde o empirismo dos ex-jogadores até o caráter lúdico e não competitivo de alguns professores de Educação Física, com ambos se preocupando pouco com a parte física, visto que o foco são os aspectos técnicos e coletivos do futebol.

Fonte: adaptado de Moraes (2015). 


\section{Escolinhas não Seletivas}

As escolinhas não seletivas foram criadas pelo Estado, principalmente pelos municípios, e por organizações não governamentais (ONGs) para suprir a ausência dos antigos espaços de lazer das crianças e adolescentes, como a várzea e a rua (Melo, 2008).

As mesmas também visam complementar a formação por meio da socialização, motivação, inclusão e elevação da autoestima, com a realização de atividades pedagógicas, artísticas e culturais, incentivando a prática educacional e não só o ensino do futebol, com a participação, em muitos casos, atrelada à frequência escolar (Casarin \& Cella, 2008; Melo, 2008; Scaglia, 1996).
Melo (2008), Scaglia (1996) e Valentin \& Coelho (2005) apontam que a importância desse formato de escolinha reside em direcionar a atenção e energia das crianças e adolescentes para o esporte, em especial ao futebol pois, além de propiciar uma opção de lazer a esses jovens, concede uma experiência educacional ampla, capaz de direcioná-los a uma vida honesta e promissora, afastando-os de problemas como a violência, drogas e demais vícios. Tais escolinhas também atraem a atenção e a participação dos familiares dos alunos, que são afetados positivamente pelas mesmas, além aproximar toda a comunidade. No Quadro 3 apresentamos as principais características das escolinhas não seletivas comuns.

Quadro 3 - Características das escolinhas não seletivas

Não gera retorno financeiro e custos aos alunos;

Ligadas aos governos, principalmente municipais, e a ONGs;

Estrutura física limitada;

Comissão técnica formada apenas pelo professor;

Materiais esportivos de baixa qualidade, em quantidade limitada e fornecidos gratuitamente; Competições raras;

Metodologia baseada em uma pedagogia de formação ampla do cidadão aplicada através de atividades

diversificadas que desenvolvam a totalidade, não focando apenas o ensino do futebol.

Fonte: adaptado de Casarin and Cella (2008) e Moraes (2015).

Por fim, destacamos que nesse período a conquista da Copa do Mundo de 1994 consolidou o "futebol força" como estilo predominante no Brasil, com expansão das alternativas para a formação do jogador de futebol. Essa formação é baseada totalmente no jogo coletivo e tático, com forte valorização da preparação física e paralelo afastamento dos princípios do "futebol arte" (Rodrigues, 2003; Sarmento, 2006).

\section{8 - Ao Presente}

A continuidade da expansão mundial do futebol no final do século XX e início do XXI abriu novos mercados, como o asiático, do Leste Europeu e dos Estados Unidos, aumentando a demanda internacional por jogadores, o valor das transferências e incentivando, ainda mais, o rentável negócio da formação e comercialização de atletas no Brasil (Campestrini, 2009; Jacobs \& Duarte, 2006; Soares et al., 2011).

A formação como negócio (a partir da identificação e do desenvolvimento de novos jogadores) foi potencializada com a criação, em 1998, da Lei n ${ }^{\circ} 9.615$ (Lei Pelé), que alterou a relação de trabalho entre clubes

\footnotetext{
${ }^{10}$ A criação de clubes-empresa, ou seja, clubes com fins
} lucrativos no formato de sociedades anônimas (S/A), foi e atletas; facilitou e criou novas possibilidades de atuação e negócios para empresários/agentes de jogadores; e iniciou um lento processo de regulamentação da formação. Outro aspecto relevante foi a possibilidade de transformação dos clubes de futebol em empresas e a criação de clubes-empresa ${ }^{10}$ por empresários de atletas e investidores (Brasil, 1998; Melo Filho, 2011), traçando novas perspectivas para o processo de formação de jogadores.

\section{Clubes-Empresa}

Grande parte dos clubes-empresa, criados principalmente a partir de 1998, são voltados exclusivamente para a formação e comercialização de atletas, com seus proprietários atuando em todas as etapas, desde a seleção dos jovens, passando pelo controle do ensino até a "venda" dos mesmos para clubes do exterior (Damo, 2007; Paoli, 2007).

Os clubes-empresa implementaram seus próprios CTs, dotados de uma estrutura ampla e moderna e com equipes multidisciplinares, sendo utilizada uma

prevista em 1993 na Lei $n^{\circ} 8.672$ (Lei Zico), sendo regulamentada e ganhando amplitude a partir da Lei $\mathrm{n}^{\circ}$ 9.615 (Lei Pelé). 
metodologia fundamentada "no modelo de empresa-militarizada" (Rodrigues, 2003, p. 101), na qual são formados jogadores visando futuras transferências comerciais.

Segundo Rodrigues (2007), nesses clubes são criados "jogadores-máquinas" capazes de atuar em diversas posições com excelente porte e preparo físico, com a formação baseada na necessidade de cada posição e de cada mercado consumidor. É exigido dos jovens obediência aos esquemas táticos, ao jogo coletivo e um comportamento exemplar, em que a paciência, o fair play e uma vida pacata e discreta fora de campo são considerados fundamentais para o sucesso e a garantia de altos lucros aos investidores (Rodrigues, 2007).
Os clubes-empresa adquiriram relevância no cenário futebolístico brasileiro e se tornaram um dos principais locais de formação de jogadores. Como exemplos bem-sucedidos podemos citar o Grêmio Esportivo Anápolis, de Goiás; o Fragata, do Rio Grande do Sul; o Desportivo Brasil, de São Paulo; e o Paraná Soccer Technical Center, do Paraná. No Quadro 4 são apresentadas as principais características da formação realizada atualmente pelos clubes-empresa.

Quadro 4 - Características da formação dos clubes-empresa

Visam obter altos lucros com a transferência de jogadores, principalmente para o exterior; Ligados a empresários e investidores;

Estrutura física completa e em muitos casos superior à das categorias de base dos clubes tradicionais;

Comissão técnica ampla e formada por profissionais qualificados de diversas áreas;

Materiais esportivos de alta qualidade, em quantidade suficiente e fornecidos pelo clube;

Competições durante toda a temporada, inclusive com participação frequente em campeonatos internacionais como forma de exibição do "produto";

Metodologia de ensino/treinamento baseada no "futebol força", com valorização do coletivo, do preparo físico e de jogadores técnicos e aptos a jogarem em diversas posições. Os aspectos comportamentais são valorizados com preferência por jogadores com bom comportamento e discretos. Fonte: adaptado de Moraes (2015).

\section{Processo de Formação Atual}

Sobre o atual processo de formação de jogadores de futebol no Brasil, podemos apontar que se manteve o formato com as categorias de base dos clubes e as escolinhas seletivas privadas como os principais locais de ensino e formação. Estas últimas têm tido crescimento expressivo tanto em número de alunos como em unidades, espalhando-se por todo o país e atraindo novos investidores, interessados nos possíveis lucros (Ferreira, 2010). Identificamos ainda como importante local de formação os clubes-empresa, que, como citado, rapidamente adquiriram relevância no processo de formação. Por fim, as escolinhas não seletivas continuam a existir, atuando de forma mais direcionada à formação educacional e social.

Em que pesem as diferenças de origem, estrutura e proprietários, as categorias de base dos clubes e os clubes-empresa visam o mesmo objetivo: a formação e "venda" de atletas (Cruz, 2012). A formação em ambas as instituições tem como foco a fase final do processo, a partir dos 13/14 anos (Carraveta, 2012), quando os atletas são selecionados ainda por meio das citadas "peneiras" (Pedroza Junior, 2013).

Tanto os clubes de futebol como os clubes-empresa utilizam equipes multidisciplinares compostas por desde preparadores físicos até educadores e assistentes sociais (Cruz, 2012) visando maximizar todos os aspectos relacionados à "produção" de atletas polivalentes adequados às exigências do mercado, principalmente o internacional, garantindo elevados lucros (Damo, 2007; Paoli, 2007).

Durante a formação são abordados aspectos físicos, técnicos, táticos, sociais e comportamentais, em um processo longo, desgastante e competitivo que não garante o retorno do investimento e que todos os jovens sejam profissionalizados (Cavichiolli et al., 2011; Damo, 2007; Mascarenhas, 2014; Spaggiari, 2009). Comumente são utilizadas três metodologias de ensino e treinamento: a pré-científica; a científica, dividida em global e específica; e a sistêmica (Carraveta, 2012; Rodrigues, 2003).

As etapas do atual processo de formação são definidas e descritas no modelo de funil da formação desenvolvido por Damo (2007) (Figura 1), sendo possível observar que o modelo determinada o início como préformação, realizada nas escolinhas entre os cinco e 14 anos. 


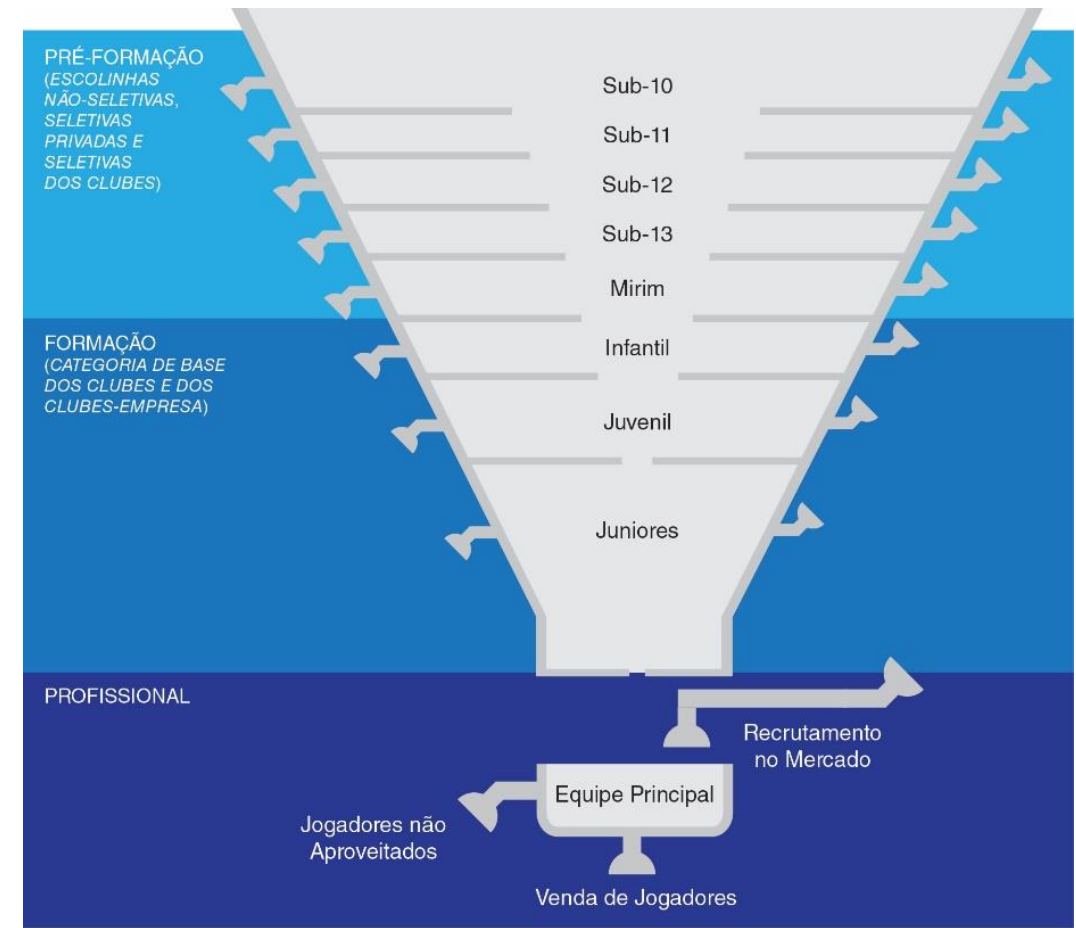

Figura 1 - Etapas do processo de formação

Fonte: Adaptado de Damo (2007).

Entre os 13 e 14 anos os adolescentes são selecionados pelos clubes e/ou clubes-empresa e os aprovados passam a integrar as categorias de base, onde realizam a parte final da formação. Essa etapa é composta por três categorias - sub 15,17 e 20 - e os que chegam ao final do processo são considerados aptos a se tornarem profissionais. Durante o processo é constante a entrada, saída e "venda" de atletas.

$\mathrm{O}$ atual processo de formação é alvo de diversas críticas, como a mercantilização dos jogadores; denúncias de exploração e abuso dos jovens; ausência de metodologia clara e de estrutura completa em grande parte dos clubes e escolinhas; pouca atenção dos jovens e dos responsáveis em relação à formação e escolarização; influência negativa dos familiares ao "forçarem" os jovens a serem jogadores; e o baixo aproveitamento e qualidade dos atletas ao final do processo (Amora, 2013; Campestrini, 2009; Casarin \& Streit, 2011; R. T. Cruz, 2011; Damo, 2007; Mascarenhas, 2014; Rocha et al., 2011; Santos et al., 2011; Soares et al., 2011).

\section{Certificado de Clube Formador}

Como tentativa de resolver os problemas citados, foi promulgada, em 2011, a Lei ${ }^{\circ} 12.395$ que altera a Lei ${ }^{\circ} 9.615$ (Lei Pelé), especialmente o artigo 29, que trata da formação, estabelecendo normas e instrumentos

\footnotetext{
${ }^{11}$ Para mais informações sobre o Certificado de Clube Formador, suas exigências e aplicação consultar Moraes (2015).
}

legais para proteger clubes e jovens atletas (Brasil, 2011).

Dentre as diversas inovações, destaque para a criação do Certificado de Clube Formador (CCF), que objetiva a emissão de um documento que atesta que o clube é formador de atletas. Para tal, o clube deve cumprir uma série de exigências ${ }^{11}$ que visam padronizar e possibilitar uma formação esportiva ampla e completa, por meio do oferecimento de condições para o desenvolvimento de aspectos técnicos, suporte médico e psicológico e promoção social e educacional (Brasil, 2011; Melo Filho, 2011; Moraes, 2015).

O Certificado de Clube Formador ainda é necessário para que o clube obtenha outros benefícios legais relacionados à formação, como o Contrato de Formação Desportiva; o direito de preferência na assinatura do primeiro Contrato Profissional e na primeira renovação do mesmo; e o Mecanismo de Solidariedade Interno (Melo Filho, 2011; Moraes, 2015).

O CCF é valido para todas as modalidades esportivas, e no futebol a sua emissão e controle é de responsabilidade da CBF (Brasil, 2011). A entidade regulamentou o tema em 2012 por meio da Resolução da Presidência $n^{\circ} 01 / 2012$. Tal documento acrescentou exigências, determinou como devem ser os procedimentos de certificação e repassou parte da responsabilidade pelo 
processo às Federações estaduais (Confederação Brasileira de Futebol, 2012).

O processo de certificação teve início efetivamente em 2012 e, segundo a CBF, em outubro de 2015 estavam certificados 43 clubes dos 783 clubes de futebol presentes no Cadastro Nacional de Clubes de Futebol (CNCF) da CBF (Confederação Brasileira de Futebol, 2009), sendo os certificados de 11 estados do Brasil (Assessoria CBF, 2015b).

\section{CONSIDERAÇÕES FINAIS}

Com base nas informações obtidas nos trabalhos identificados na revisão sistemática de literatura foi possível responder à primeira questão desta pesquisa: como ocorreu a evolução histórica do processo de formação de jogadores no Brasil, com ênfase nas suas etapas, locais de aprendizagem, agentes educadores e metodologias.

Assim, foi demonstrado que o processo de formação brasileiro partiu de um modelo elitista, realizado principalmente nos clubes socioesportivos, para um popular, informal e livre, realizado nas ruas e campos de várzea, até se tornar totalmente formalizado, restrito, baseado em métodos científicos e inspirado no chamado "futebol força". Atualmente, tal processo é realizado principalmente nas categorias de base dos clubes e dos clubes-empresa e objetiva a formação de jogadores para a comercialização.

Também foram expostos os problemas que cercam o processo de formação e que a regulamentação do mesmo é recente e ainda não é aplicada de forma ampla, em especial com relação ao Certificado de Clube Formador, limitado a poucos clubes brasileiros.

Para cumprimos o outro objetivo desta pesquisa, apresentamos, no Quadro 6, uma síntese do processo histórico da formação de jogadores no Brasil. A mesma foi elaborada com base na ordem cronológica dos acontecimentos, sendo dividida em cinco etapas, além de ser composta por um nome ilustrativo para cada fase $^{12}$. Estão contidos os principais locais de formação, agentes educadores e as principais metodologias de ensino utilizadas em cada período.

\footnotetext{
${ }^{12} \mathrm{O}$ nome concedido a cada etapa possui apenas função ilustrativa e está relacionado a uma característica principal de cada respectivo período do processo de formação brasileiro.
} 
Quadro 6 - Síntese do processo histórico da formação de jogadores de futebol no Brasil

\begin{tabular}{|c|c|c|c|c|}
\hline Época & Período & Principais locais & Principais agentes educadores & Principais metodologias de ensino \\
\hline $1880-1930$ & Observação & $\begin{array}{l}\text { Escolas, clubes } \\
\text { socioesportivos e } \\
\text { fábricas. }\end{array}$ & $\begin{array}{l}\text { Imigrantes, padres, profes sores } \\
\text { escolares, praticantes e jovens da } \\
\text { elite. }\end{array}$ & $\begin{array}{l}\text { Pré-científica. Livre, por meio da } \\
\text { observação e aprendizagem dos } \\
\text { fundamentos e regras. }\end{array}$ \\
\hline $1930-1966$ & Prática & $\begin{array}{c}\text { Rua e campos de } \\
\text { várzea. }\end{array}$ & $\begin{array}{l}\text { O próprio jogador por meio da } \\
\text { prática e do contato com outros } \\
\text { jogadores. }\end{array}$ & $\begin{array}{l}\text { Pré-científica. Por meio da prática, } \\
\text { com liberdade, improviso e } \\
\text { criatividade. Baseado no "futebol } \\
\text { arte" e no individualismo. }\end{array}$ \\
\hline $1966-1990$ & Cientificação & $\begin{array}{l}\text { Escolinhas dos } \\
\text { clubes. }\end{array}$ & $\begin{array}{c}\text { Funcionários dos clubes, } \\
\text { principalmente ex-atletas e } \\
\text { graduados em Educação Física. }\end{array}$ & $\begin{array}{l}\text { Científica. Bas eado no "futebol } \\
\text { força", com uso de métodos } \\
\text { científicos e esquemas táticos, na } \\
\text { parte física e no coletivo em } \\
\text { detrimento ao individual. }\end{array}$ \\
\hline $1990-1998$ & Escolinhas & $\begin{array}{l}\text { Categorias de base } \\
\text { dos clubes e } \\
\text { escolinhas seletivas } \\
\text { privadas. }\end{array}$ & $\begin{array}{l}\text { Ex-atletas e professores de } \\
\text { Educação Física. }\end{array}$ & $\begin{array}{l}\text { Científica (global ou específica). } \\
\text { Baseada no "futebol força", como } \\
\text { início da utilização de equipes } \\
\text { multidisciplinares, de novos } \\
\text { avanços científicos e } \\
\text { aprofundamento do uso dos CTs. }\end{array}$ \\
\hline $\begin{array}{l}1998-\text { ao } \\
\text { presente }\end{array}$ & $\begin{array}{l}\text { Regulamentação e } \\
\text { Negócio }\end{array}$ & $\begin{array}{l}\text { Categorias de base } \\
\text { dos clubes e dos } \\
\text { clubes-empresa. }\end{array}$ & $\begin{array}{l}\text { Equipes multidisciplinares } \\
\text { compostas principalmente por } \\
\text { professores de Educação Física, } \\
\text { médicos, fisioterapeutas, } \\
\text { psicólogos, educadores e } \\
\text { assistentes sociais. }\end{array}$ & $\begin{array}{l}\text { Sistêmica. Mercantilização total, } \\
\text { multidisciplinar, "futebol força", } \\
\text { valorização da polivalência, } \\
\text { obediência tática, preparo físico e } \\
\text { comportamento exemplar dentro e } \\
\text { fora de campo. }\end{array}$ \\
\hline
\end{tabular}

Fonte: elaborado pelos autores.

Ao cumprir seus objetivos iniciais, este trabalho se soma aos estudos sobre o processo de formação de jogadores de futebol no Brasil, demostrando claramente, e de forma cronológica, todos os seus períodos, locais de realização, agentes educadores e principais metodologias.

A realização deste estudo considerou a importância da formação não só para o futebol, mas para toda a sociedade brasileira. Ao finalizarmos essa pesquisa, fica ainda mais evidente tal relevância e a necessidade de a gestão do esporte brasileiro estudar, analisar e repensar o processo de formação de crianças e adolescentes nas diferentes modalidades, e no caso do futebol, com menos preocupação na obtenção de lucro e mais na qualidade de todo o processo, tanto no aspecto técnico quanto no social e educacional.

Assim, esperamos que este estudo, em especial a síntese apresentada, venha a servir de base para futuras pesquisas sobre a formação de futebolistas no Brasil, a incentivar novos estudos que aprofundem os conhecimentos sobre cada período apresentado e que possa balizar as ações práticas de forma que sejam formados não apenas jogadores talentosos, como os do passado, mas também cidadãos com um futuro não só esportivo. 


\section{REFERÊNCIAS}

Aidar, A. C. K., \& Leoncini, M. P. (2002). Evolução do futebol e do futebol como negócio. In A. C. K. Aidar, M. P. Leoncini, \& J. J. Oliveira (Ed.). A nova gestão do futebol (2a . ed., pp. 79-100). Rio de Janeiro: Editora FGV.

Amora, D. (2013, Out. 18). Pesquisa aponta tráfico de pessoas no Brasil até para futebol. Folha de S. Paulo. Disponível em: http://goo.g1/zD8UP4

Assessoria CBF. (2015a, Jul. 21). Transferências para o exterior: números do mercado da bola. CBF.com.br. Disponível em: http://goo.gl/nKGili

Assessoria CBF. (2015b, Out. 1). CBF divulga lista de clubes formadores cadastrados. $C B F$.com.br. Disponível em: http://goo.gl/WsRIEv

Brasil. (1998). Lei $\mathrm{n}^{\circ} 9.615$, de 24 de março de 1998. Institui normas gerais sobre desporto e dá outras providências. Diário Oficial [da] República Federativa do Brasil. Disponível em: http://goo.gl/7mTa8k

Brasil. (2011). Lei $\mathrm{n}^{\circ} 12.395$ de 16 de março de 2011. Altera as Leis $\mathrm{n}^{0} 9.615$, de 24 de março de 1998, que institui normas gerais sobre desporto, e $\mathrm{n}^{\mathrm{o}}$ 10.891, de 9 de julho de 2004, que institui a BolsaAtleta; cria os Programas Atleta Pódio e Cidade Esportiva; revoga a Lei $n^{\circ} 6.354$, de 2 de setembro de 1976; e dá outras providências. Diário Oficial [da] República Federativa do Brasil. Disponível em: http://goo.gl/lmZ0xT

Brunoro, J. C., \& Afif, A. (1997). Futebol $100 \%$ profissional. São Paulo: Editora Gente.

Campestrini, G. R. H. (2009). A reponsabilidade social na formação de praticantes para o futebol: análise do processo deformação em clubes brasileiros (Dissertação de mestrado, Universidade Técnica de Lisboa). Disponível em: http://goo.gl/0B2lkq

Carraveta, E. (2006). Modernização da gestão no futebol brasileiro: perspectivas para a qualificação do rendimento competitivo. Porto Alegre: AGE Editora.

Carraveta, E. (2012). Futebol: A formação de times competitivos. Porto Alegre: Sulina.

Casarin, R. V., \& Cella, M. T. (2008). Análise das sessões de treinamento de futebol entre categorias de base e escolinhas (Trabalho de conclusão de curso, Universidade do Oeste de Santa Catarina). Disponível em: http://goo.gl/AE5gZF

Casarin, R. V., \& Streit, I. (2011). Modelo de formação em futebol: Análise de clubes do estado do Rio Grande do Sul. Revista Brasileira de Futsal e Futebol, 3 (7), 45-57. Disponível em: http://goo.gl/5DXt9b

Cavichiolli, F. R., Cheluchinhak, A. B., Capraro, A. M., Marchi Junior, W., \& Mezzadri, F. M. (2011). O processo de formação do atleta de futsal e futebol: análise etnográfica. Res. Bras. Educ. Fis. Esporte, 25 (4), 631-647. Disponível em: http://goo.gl/PdsF15

Coelho, P. V. (2014a, Dez. 10). Vexame histórico na Copa mostrou que o Brasil não ensina mais futebol. Folha de S. Paulo. Disponível em: http://goo.gl/Bp5SvX

Coelho, P. V. (2014b, Dez. 14). Vexame na Copa mostra que Brasil não ensina mais futebol Parte 2. Folha de S. Paulo. Disponível em: http://goo.gl/lfVAve

Confederação Brasileira de Futebol. (2009). Cadastro Nacional de Clubes de Futebol (CNCF). Cidadeverde.com. Disponível em: http://goo.gl/bVcoMH

Confederação Brasileira de Futebol. (2012, Dez. 23). Resolução da Presidência $n^{\circ}$ 01/2012, de 17 de janeiro de 2012. Estabelece normas, procedimentos, critérios e diretrizes para emissão do Certificado de Clube Formador (CFF) pela CBF, e delega às Federações Estaduais poderes para emitir prévio parecer conclusivo (Anexo I) para fins de certificação referente às suas entidades de prática desportiva filiadas, à vista dos critérios e diretrizes constantes no Anexo II. CBF.com.br. Disponível em: http://goo.gl/sAsmxz

Cruz, R. M. (2012). A formação de atletas de futebol: um estudo na categoria sub-15 do Cruzeiro Esporte Clube, Belo Horizonte-MG. Revista Brasileira de Futsal e Futebol, 4 (13), 189-194. Disponível em: http://goo.gl/4A9NmY

Cruz, R. T. (2011). Influência em participar da escolinha de futebol. Revista Brasileira de Futsal e Futebol, 3 (10), 281-289. Disponível em: http://goo.gl/J1DKGZ 
Damo, A. S. (2007). Do dom à profissão: A formação de futebolistas no Brasil e na França. São Paulo: Aderaldo \& Rithschild Ed., Anpocs.

Ferreira, A. d. O. (2010). Futebol, tecnologia e aprendizagem: corpo, performance e criatividade (Dissertação de mestrado, Pontifícia Universidade Católica de São Paulo). Disponível em: http://goo.gl/irBDw1

Ferreira, D. P., \& Paim, M. C. C. (2011). Estruturação das categorias de base no futebol. EFDeportes.com, 158. Disponível em: http://goo.gl/n8CbcP

Franzini, F. (2003). Corações na ponta de chuteira: Capítulos iniciais da história do futebol brasileiro (1919-1938). Rio de Janeiro: DP\&A.

Gaspar, V. N. (2011). As implicações das abordagens pedagógicas na formação de jogadores de futebol. Revista Brasileira de Futsal e Futebol, 3 (10), 275-280. Disponível em: http://goo.gl/F4aTmY

Gomes, I. S., \& Caminha, I. d. O. (2014). Guia para estudos de revisão sistemática: uma opção metodológica para as Ciências do Movimento Humano. Movimento, 20 (1), 395-411. Disponível em: http://goo.gl/xLtnxc

Jacobs, C. S., \& Duarte, F. (2006). Futebol exportação. Rio de Janeiro: Editora Senac Rio.

Lance! Contéudos. (2016, Jun. 2). Argentina segue na liderança do ranking da Fifa; Brasil é o sétimo. UOL Esporte Futebol. Disponível em: http://goo.gl/MiQE2m

Mascarenhas, G. (2014). Entradas $e$ bandeiras: a conquista do Brasil pelo futebol. Rio de Janeiro: EdUERJ.

Melo, M. L. (2008). Importância das escolinhas de futebol na formação do jovem atleta em Campina Grande - PB (Dissertação de mestrado, Universidade Federal da Paraíba). Disponível em: http://goo.gl/pZ47qu

Melo Filho, Á. (2011). Nova Lei Pelé: Avanços e impactos. Rio de Janeiro: Maquinária.

Montagner, P. C., \& Oliveira Silva, C. C. (2003). Reflexões acerca do treinamento a longo prazo e a seleção de talentos através de "peneiras" no futebol. Revista Brasileira de Ciências do Esporte, 24(2), 187-200. Disponível em: http://goo.gl/3LwPQo
Moraes, I. F. (2015). Formação de jogadores de futebol no Brasil: Da implementação às perspetivas futuras do Certificado de Clube Formador (Dissertação de mestrado, Universidade do Porto). Disponível em: http://goo.gl/71Pr5e

Paoli, P. B. (2007). Os estilos de futebol e os processos de seleção e deteç̧ão de talentos (Tese de doutorado, Universidade Gama Filho). Disponível em: $\quad$ http://labec-ufrj.com/teses/ tesepaoli.pdf

Pazzin, T. R. B. (2014). Escolas de futebol: uma pesquisa sobre a formação dos treinadores e metodologia utilizada nas escolas de futebol de cidades do litoral norte do Rio Grande do Sul. Revista Brasileira de Futsal e Futebol, 6(22), 271277. Disponível em: http://goo.gl/3Oe5WG

Pedroza Junior, E. T. (2013). Processo de seleção e captação de atletas de futebol de campo na categoria sub-15 em Pernambuco. Revista Brasileira de Futsal e Futebol, 5 (16), 155-163. Disponível em: http://goo.gl/A4IGmg

Pimenta, C. A. M. (2000). Novos Processos de Formação de Jogadores de Futebol e o fenômeno das "escolinhas": Uma análise crítica do possível. In P. Alabarces (Ed.), Peligro de Gol. Estudios sobre deporte y sociedad en América Latina (pp. 75-97). Buenos Aires: CLACSO, Consejo Latinoamericano de Ciencias Sociales.

Rocha, H., P. A. da, Bartholo, T. L., Melo, L. B. S. d., \& Soares, A. J. G. (2011). Jovens esportistas: profissionalização no futebol e a formação na escola. Motriz, 17 (2), 252-263. Disponível em: http://goo.gl/sa0MUj

Rodrigues, F. X. F. (2003). A formação do jogador de futebol no Sport Club Internacional (1997-2002) (Dissertação de mestrado, Universidade Federal do Rio Grande do Sul). Disponível em: http://goo.gl/wp6XHd

Rodrigues, F. X. F. (2007). O fim do passe e a modernização conservadora no futebol brasileiro (2001-2006) (Tese de doutorado, Universidade Federal do Rio Grande do Sul). Disponível em: http://goo.gl/vmQcrS

Santiago Júnior, J. R. S. (2006). Os arquivos dos campeonatos brasileiros. São Paulo: Panda Books.

Santos, A. R. d., Eugênio, J. F., Souza, R. A., Liberali, R., \& Almeida, R. d. (2011). A influência familiar em atletas de categoria de base no futebol. 
Revista Brasileira de Futsal e Futebol, 3(8), 83-88. Disponível em: http://goo.gl/7iYJ69

Santos Neto, J. M. d. (2002). Visão do Jogo: Primórdios do futebol no Brasil. São Paulo: Cosac \& Naify.

Sapienza, V. (2011, Maio 17). A Lei Pelé precisa ser alterada. Assembleia Legislativa do Estado de São Paulo. Disponível em: http://goo.gl/uXt9D8

Sarmento, C. E. (2006). A regra do jogo: uma história institucional da CBF. Rio de Janeiro: CPDOC.

Scaglia, A. J. (1996). Escolinha de Futebol: Uma questão pedagógica. Motriz, 2 (1), 36-43. Disponível em: http://goo.gl/xapC0p

Silva, D. A. S. (2008). Evolução histórica da legislação esportiva brasileira: Do Estado Novo ao século XXI. Revista Brasileira de Educação Física, Esporte, Lazer e Dança, 3 (3), 69-78. Disponível em: http://goo.gl/oqZvy7

Soares, A. J. G., Melo, L. B. S. d., Costa, F. R. d., Bartholo, T. L., \& Bento, J. O. (2011). Jogadores de futebol no Brasil: Mercado, formação de atletas e escola. Revista Brasileira de Ciências do Esporte, 33 (4), 905-921. Disponível em: http://goo.gl/AsZZju

Solder, P. A., Menezes, G. B. d., Yoshida, G. M. V., \& Moreira, M. d. S. G. (2010). Escolinhas de futebol. Revista Brasileira de Futsal e Futebol, 2 (6), 135-145. Disponível em: http://goo.gl/iDwQa6

Souza, P. A. R. d. (2008). A prata da casa: A "mercadoria força de trabalho jogador de futebol" no Brasil pós Lei Pelé (Dissertação de mestrado, Universidade Federal da Bahia). Disponível em: http://repositorio.ufba.br/ri/handle/ri/12860

Spaggiari, E. (2009). Tem que ter categoria: construção do saber futebolistico (Dissertação de mestrado, Universidade de São Paulo). Disponível em: http://goo.gl/40XoqZ

Stédile, M. E. A. (2011). Da fábrica à várzea: clubes de futebol operário em Porto Alegre (Dissertação de mestrado, Universidade Federal do Rio Grande do Sul). Disponível em: http://goo.gl/N3eqVz

Thiengo, C. R. (2011). Os saberes e o processo de formação de futebolistas no São Paulo Futebol Clube (Dissertação de mestrado, Universidade
Estadual Paulista "Júlio de Mesquita Filho"). Disponível em: http://goo.gl/Vio1mw

Toledo, L. H. d. (2000). Lógicas no Futebol: Dimensões simbólicas de um esporte nacional (Tese de doutorado, Universidade de São Paulo). Disponível em: http://goo.gl/3pAuUa

Valentin, R. B., \& Coelho, M. (2005). Sobre as escolinhas de futebol: Processo civilizador e práticas pedagógicas. Motriz, 11 (3), 185-197. Disponível em: http://goo.gl/nZg9HG

Wilpert, R. A. (2005). O futebol como agente de inclusão e interação social: Um estudo de caso sobre as escolinhas de futebol de Florianópolis-SC (Dissertação de mestrado, Universidade Federal de Santa Catarina). Disponível em: http://goo.gl/4LVCE6 